2002 100: 224-229

doi:10.1182/blood.V100.1.224

\title{
Repair of DNA interstrand crosslinks as a mechanism of clinical resistance to melphalan in multiple myeloma
}

Victoria J. Spanswick, Charles Craddock, Mallika Sekhar, Prem Mahendra, Paneesha Shankaranarayana, R. George Hughes, Daniel Hochhauser and John A. Hartley

Updated information and services can be found at:

http://bloodjournal.hematologylibrary.org/cgi/content/full/100/1/224

Articles on similar topics may be found in the following Blood collections:

Neoplasia (4075 articles)

Information about reproducing this article in parts or in its entirety may be found online at: http://bloodjournal.hematologylibrary.org/misc/rights.dtl\#repub_requests

Information about ordering reprints may be found online at:

http://bloodjournal.hematologylibrary.org/misc/rights.dtl\#reprints

Information about subscriptions and ASH membership may be found online at:

http://bloodjournal.hematologylibrary.org/subscriptions/index.dtl

Blood (print ISSN 0006-4971, online ISSN 1528-0020), is published

semimonthly by the American Society of Hematology, 1900 M St, NW, Suite 200, Washington DC 20036.

Copyright 2007 by The American Society of Hematology; all rights reserved.

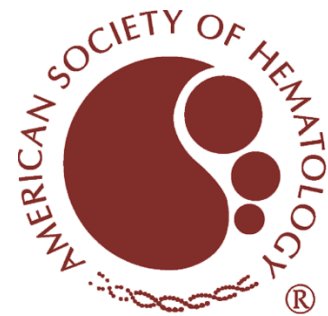




\title{
Repair of DNA interstrand crosslinks as a mechanism of clinical resistance to melphalan in multiple myeloma
}

Victoria J. Spanswick, Charles Craddock, Mallika Sekhar, Prem Mahendra, Paneesha Shankaranarayana, R. George Hughes, Daniel Hochhauser, and John A. Hartley

\begin{abstract}
Melphalan is widely used as a preparative agent in patients with multiple myeloma (MM) undergoing autologous stem cell transplantation (SCT). Although disease relapse is the major cause of death after a melphalan-conditioned autograft, the mechanism remains unclear. Melphalan produces a number of DNA adducts with the DNA interstrand crosslink (ICL) considered to be the critical cytotoxic lesion. By using a modification of the single-cell gel electrophoresis (Comet) assay, we have measured formation and repair of
\end{abstract}

DNA ICL in plasma cells from melphalannaive and melphalan-treated patients (ie, those who have relapsed after a melphalan-conditioned autologous SCT or oral melphalan therapy). Similar levels of dosedependent DNA interstand crosslinking were observed in cells from both melphalan-naive and -treated patients. However, marked differences in ICL repair were observed: cells from naive patients showed no repair, whereas those from treated patients exhibited between $42 \%$ and $100 \%$ repair at 40 hours. In vitro sensitivity to melphalan in plasma cells was found to correlate with ICL repair. These findings suggest that ICL repair may be an important mechanism by which melphalan resistance emerges after autologous SCT or oral therapy. This mechanism may have implications for MM patients undergoing melphalan therapy. (Blood. 2002;100:224-229)

(c) 2002 by The American Society of Hematology

\section{Introduction}

Despite the ability of autologous stem cell transplantation (SCT) to improve survival in patients with multiple myeloma (MM), disease relapse is almost universally observed. ${ }^{1}$ In a proportion of patients a second transplantation is performed at the time of relapse, and there is growing interest in whether tandem transplantation has the capacity to improve outcome. ${ }^{2}$ Melphalan is a highly effective alkylating agent against malignant plasma cells in vitro and has become the standard conditioning agent in patients undergoing autologous SCT. ${ }^{3}$ However, because neither the incidence nor the mechanism of resistance to melphalan is fully understood, its role as a preparative regime has not been fully defined.

Many mechanisms of drug resistance in MM have been studied. These mechanisms include alterations in drug transport by proteins such as MDR1/p-glycoprotein, ${ }^{4,5}$ enhanced drug metabolism by detoxifying enzymes such as glutathione, ${ }^{4}$ alterations in target gene expression, ${ }^{6}$ and mutations in target genes. ${ }^{7}$ Inhibition of druginduced apoptosis-dependent mechanisms has also been suggested to play a role in resistance in MM. ${ }^{8}$ However, these mechanisms may relate more to resistance to the components of the VAD regime (vincristine, adriamycin, dexamethasone) rather than melphalan.

Melphalan is a member of the nitrogen mustard class of chemotherapeutic agents and elicits its mechanism of action by the alkylation of DNA. ${ }^{9}$ It is capable of producing a number of different DNA adducts, the majority of which are monoadducts as a result of a single alkylation event. A small proportion of monoad- ducts then go on to form crosslinks as a result of a second alkylation. The formation of crosslinks between the 2 strands of DNA, interstrand crosslinking, is considered to be a critical event, and there is clear evidence that their formation and subsequent persistence correlates with in vitro cytotoxicity. ${ }^{10,11}$ In vitro resistance to nitrogen mustards has been associated with defects in drug transport systems resulting in reduced drug uptake, ${ }^{12}$ increased binding to glutathione, ${ }^{13}$ and increased repair of DNA interstrand crosslinks (ICLs). ${ }^{14,15}$ It has not been established, however, which of these mechanisms are most relevant in the clinical setting.

DNA ICL formation can be measured in plasmid DNA by using an agarose gel-based method, ${ }^{16}$ and the formation and repair of ICL in intact cells can be followed by using alkaline filter elution. ${ }^{17}$ Alkaline elution, however, requires a large number of cells and is not easily adapted for in vivo studies. The single-cell gel electrophoresis (Comet) assay was originally developed to measure DNA strand breaks in a single cell population ${ }^{18}$ and has been modified to allow the study of ICL formation and repair. ${ }^{19}$ It has the advantage of requiring few cells, and, because analysis can be made at a single-cell level, the method allows the detection of heterogeneity of response within a cell population. It is also more sensitive than other techniques used to measure ICL such as alkaline elution and allows the formation and repair of ICL to be studied in clinical material at pharmacologically relevant doses. ${ }^{20}$ For example, initial ICL formation and repair studies using in vitro cell lines and human
From the Cancer Research UK Drug-DNA Interactions Research Group, Department of Oncology, Royal Free and University College Medical School, London, United Kingdom; the Department of Clinical Haematology and Stem Cell Transplantation, University Hospital, Birmingham, United Kingdom; and the Department of Clinical Haematology, West Middlesex University Hospital, Isleworth, United Kingdom.

Submitted July 27, 2001; accepted February 19, 2002

Supported in part by the Cancer Research UK (program grant SP2000/0402 to J.A.H.) and the Leukaemia Research Fund.
Reprints: John A. Hartley, Cancer Research UK Drug-DNA Interactions Research Group, Department of Oncology, Royal Free and University College Medical School, UCL, 91 Riding House St, London, W1W 7BS, United Kingdom; e-mail: john.hartley@ucl.ac.uk.

The publication costs of this article were defrayed in part by page charge payment. Therefore, and solely to indicate this fact, this article is hereby marked "advertisement" in accordance with 18 U.S.C. section 1734.

(C) 2002 by The American Society of Hematology 
tumor xenograft models were extended to tumor biopsies from patients undergoing antibody-directed enzyme prodrug therapy phase 1 clinical trials, ${ }^{21}$ and in vivo formation of ICL has also been followed in lymphocytes taken from patients receiving ifosfamide therapy. ${ }^{20}$

In the present study we have used the Comet assay to examine formation and repair of melphalan-induced ICL in plasma cells from patients with MM following ex vivo treatment with melphalan. Two patient populations were studied: patients who had not received melphalan therapy (melphalan naive) and those treated with melphalan. The latter population includes patients who had relapsed following a high-dose melphalan-conditioned autograft and those receiving oral melphalan therapy.

\section{Patients and methods}

\section{Patients}

Twelve patients with MM were studied. Six patients were studied at diagnosis or after initial treatment with $\mathrm{VAD}^{22}$ and had never received melphalan. Six patients had relapsed following a melphalan-conditioned $\left(200 \mathrm{mg} / \mathrm{m}^{2}\right)$ autograft. One patient had received oral melphalan $\left(7 \mathrm{mg} / \mathrm{m}^{2}\right.$ per day every 5 days $\times 4$ ) in combination with prednisolone. Patient details and clinical history are summarized in Table 1.

\section{Drug treatment of plasma cells}

Plasma cells were isolated from bone marrow aspirates with the use of standard Ficoll-Hypaque centrifugation. All samples studied contained in excess of $80 \%$ plasma cells. Formation of melphalan-induced ICL was measured at concentrations ranging from 1 to $100 \mu \mathrm{M}$. Plasma cells $\left(2.5 \times 10^{4}\right.$ cells $\left./ \mathrm{mL}\right)$ in RPMI 1640 medium containing $10 \%$ fetal calf serum and $2 \mathrm{mM}$ glutamine (Autogen Bioclear, Calne, United Kingdom) were incubated with melphalan for 1 hour at $37^{\circ} \mathrm{C}$. The drug was removed by centrifugation at $200 \mathrm{~g}$ for 5 minutes, removing the supernatant and resuspending in drug-free media. Cells were incubated for a further 16 hours at $37^{\circ} \mathrm{C}$ to allow maximum formation of ICLs ( $\mathrm{t}=16$ hours). ${ }^{11}$ Repair of ICLs was studied at $50 \mu \mathrm{M}$ melphalan, a further 24 hours following maximum ICL formation ( $\mathrm{t}=40$ hours).

\section{Determination of DNA interstrand crosslinking}

The details of the single cell gel electrophoresis (Comet) assay to measure ICLs are described in detail elsewhere. ${ }^{19}$ All procedures were carried out on ice and in subdued lighting. All chemicals used were obtained from Sigma Chemical (Poole, United Kingdom) unless otherwise stated. Immediately before analysis, cells were irradiated (10 Gy) to deliver a fixed number of random DNA strand breaks. After embedding cells in $1 \%$ agarose on a precoated microscope slide, the cells were lysed for 1 hour in lysis buffer (100 mM disodium EDTA, $2.5 \mathrm{M} \mathrm{NaCl}, 10 \mathrm{mM}$ Tris-HCl, $\mathrm{pH} 10.5$ ) containing $1 \%$ Triton $\mathrm{X}-100$ added immediately before analysis and then washed every 15 minutes in distilled water for 1 hour. Slides were then incubated in alkali buffer ( $50 \mathrm{mM} \mathrm{NaOH}, 1 \mathrm{mM}$ disodium EDTA, $\mathrm{pH} 12.5$ ) for 45 minutes, followed by electrophoresis in the same buffer for 25 minutes at $18 \mathrm{~V}(0.6 \mathrm{~V} / \mathrm{cm}), 250 \mathrm{~mA}$. The slides were finally rinsed in neutralizing buffer ( $0.5 \mathrm{M}$ Tris- $\mathrm{HCl}, \mathrm{pH} 7.5)$ then saline.

After drying, the slides were stained with propidium iodide $(2.5 \mu \mathrm{g} / \mathrm{mL})$ for 30 minutes then rinsed in distilled water. Images were visualized with the use of a NIKON inverted microscope with high-pressure mercury light source (NIKON UK Limited, Kingston Upon Thames, United Kingdom), 510 to $560 \mathrm{~nm}$ excitation filter, and $590 \mathrm{~nm}$ barrier filter at $\times 20$ magnification. Images were captured by using an on-line charge-coupled device (CCD) camera and analyzed by using Komet Analysis software (Kinetic Imaging, Liverpool, United Kingdom). For each duplicate slide 25 cells were analyzed. The tail moment for each image was calculated by using the Komet Analysis software as the product of the percentage DNA in the comet tail and the distance between the means of the head and tail distributions, based on the definition of Olive et al. ${ }^{23}$ Crosslinking was expressed as the percentage decrease in tail moment compared with irradiated controls calculated by the following formula: percentage of decrease in tail moment $=[1-(\mathrm{TMdi}-\mathrm{TMcu} / \mathrm{TMci}-\mathrm{TMcu})] \times 100$; where TMdi equals tail moment of drug-treated irradiated sample, TMcu equals tail moment of untreated unirradiated control, and TMci equals tail moment of untreated irradiated control.

Repair at time $=40$ hours following exposure to $50 \mu \mathrm{M}$ melphalan and subsequent irradiation was calculated as a percentage by the following formula: percentage of repair $=\left(\mathrm{PD}_{16}-\mathrm{PD}_{40} / \mathrm{PD}_{16}\right) \times 100$; where $\mathrm{PD}_{16}=$ percentage decrease in tail moment at 16 hours and $\mathrm{PD}_{40}=$ percentage decrease in tail moment at 40 hours.

\section{In vitro cytotoxicity}

The methyl-thiazole-tetrazolium (MTT) cytotoxicity assay was carried out as previously described. ${ }^{24}$ Plasma cells $\left(1.5 \times 10^{6}\right.$ cells $\left./ \mathrm{mL}\right)$ were exposed to varying concentrations of melphalan in 96-well plates $(200 \mu \mathrm{L} /$ well $)$ and incubated at $37^{\circ} \mathrm{C}, 5 \% \mathrm{CO}_{2}$ for 72 hours. Then $50 \mu \mathrm{L} 3 \mathrm{mg} / \mathrm{mL}$ MTT (Sigma Chemical) was added to each well and incubated for an additional 4 hours. After centrifugation the supernatant was removed and the formazan crystals were dissolved in $200 \mu \mathrm{L}$ dimethlysulphoxide (VWR International Limited, Poole, United Kingdom) and $25 \mu \mathrm{L}$ Sorenson glycine buffer. The OD $570 \mathrm{~nm}$ was then measured and the dose giving $50 \%$ inhibition of cell growth $\left(\mathrm{IC}_{50}\right)$ was calculated.

Table 1. Patient disease characteristics and previous treatment regimes

\begin{tabular}{|c|c|c|c|c|c|c|c|c|}
\hline Patient & $\begin{array}{c}\text { Age, } \\
y\end{array}$ & Sex & $\begin{array}{c}\text { Stage at } \\
\text { diagnosis }\end{array}$ & Paraprotein type & $\begin{array}{l}B_{2} M \\
(g / L)\end{array}$ & $\begin{array}{c}\text { Prior } \\
\text { therapy }\end{array}$ & Autograft/no. & $\begin{array}{l}\text { Time for relapse } \\
\text { after autograft }\end{array}$ \\
\hline 1 & 46 & $M$ & IIIA & $\kappa$ free light chain & $<1$ & None & No & $N / A$ \\
\hline 2 & 61 & $M$ & IIIB & $B J_{\kappa}$ & 29.8 & VAD $\times 3$ & No & $N / A$ \\
\hline 3 & 66 & $\mathrm{~F}$ & IIIA & $\lg G_{\kappa}$ & 2.5 & None & No & $\mathrm{N} / \mathrm{A}$ \\
\hline 4 & 56 & M & IIIA & $\lg G_{\kappa}$ & 5.5 & VAD $\times 4$ & No & $\mathrm{N} / \mathrm{A}$ \\
\hline 5 & 72 & $\mathrm{M}$ & MGUS & $\lg G_{\kappa}$ & 5.9 & None & No & $\mathrm{N} / \mathrm{A}$ \\
\hline 6 & 61 & $\mathrm{~F}$ & II & $\lg G_{\kappa}$ & 8.1 & None & No & $\mathrm{N} / \mathrm{A}$ \\
\hline 7 & 59 & $\mathrm{~F}$ & 1 & $\lg G \lambda$ & 2.3 & VAD $\times 3$ & Yes/1 & 8 months \\
\hline 8 & 55 & $M$ & IIIA & $\lg G$ & 8.6 & CVAMP $\times 6$ & Yes/1 & 18 months \\
\hline 9 & 41 & $M$ & IIIB & $\lg G_{\kappa}$ & 4.4 & VAMP $\times 6$ & Yes/2 & 8 months \\
\hline 10 & 55 & $\mathrm{M}$ & IIIA & NS & 1.8 & VAD $\times 5$ & Yes/1 & 43 months \\
\hline 4 & 56 & $\mathrm{M}$ & IIIA & $\lg G_{\kappa}$ & * & VAD $\times 4$ & Yes/2 & 11 months \\
\hline 11 & 41 & $\mathrm{~F}$ & IIIA & $\lg A \lambda$ & 3.0 & CVAMP $\times 6$ & Yes/1 & 7 months \\
\hline 12 & 70 & $M$ & IIIA & $\lg A \lambda$ & 3.5 & $M+P$ & No & $\mathrm{N} / \mathrm{A}$ \\
\hline
\end{tabular}

B2M, beta-2-microglobulin; N/A, not applicable; BJ, Bence-Jones; VAD, vincristine + adriamycin + dexamethasone; IgGк, immunoglobulin Gк; MGUS, monoclonal gammopathy of unknown significance; CVAMP, cyclophosphamide + vincristine + adriamycin + methylprednisolone; VAMP, vincristine.

*Not performed as sample taken prior to second assay. 


\section{Results}

\section{DNA ICL formation in plasma cells}

DNA ICL formation in isolated plasma cells from melphalan naive and treated patients was detected by using the modified Comet assay. Cells were treated with melphalan for 1 hour followed by 16 hours drug-free after incubation. This time has previously been shown to be the peak time of crosslink formation for melphalan in cell lines ${ }^{11}$ and was confirmed for myeloma cells in the present study (data not shown).

Examples of typical Comet images are shown in Figure 1. In control nondrug treated, unirradiated plasma cells no DNA damage was detected, and the high-molecular-weight supercoiled DNA remained intact as shown in Figure 1A. Following irradiation of cells with 10 Gy to introduce a fixed level of random DNA single strand breaks, the resulting shorter fragments of DNA migrated from the bulk of the DNA during electrophoresis to produce the typical comet images (Figure 1B). The extent of DNA damage was quantitated by image analysis to produce a tail moment, defined as the product of the percentage DNA in the comet tail and the distance between the means of the head and tail distributions, based on the definition of Olive et al. ${ }^{23}$ Following ex vivo treatment with $50 \mu \mathrm{M}$ melphalan, no drug-induced single strand breakage was detected in unirradiated cells (Figure 1C), and these cells showed similar profiles to the nondrug-treated controls (Figure 1A). When the drug-treated cells were irradiated (Figure 1D), comet tails were visible but with decreased length and intensity compared with irradiated controls. The comet heads were larger and of greater intensity compared with the nondrug treated irradiated control cells (Figure 1B) because of the retention of DNA by the melphalaninduced ICLs. The decrease in comet tail moment compared with nondrug-treated irradiated controls was used to quantitate the level of DNA interstrand crosslinking.

The sensitivity of the Comet assay to detect melphalan-induced ICLs in plasma cells from a single patient is illustrated in Figure 2. A linear decrease in tail moment was observed with increasing doses of melphalan, and ICLs could be easily detected at levels as
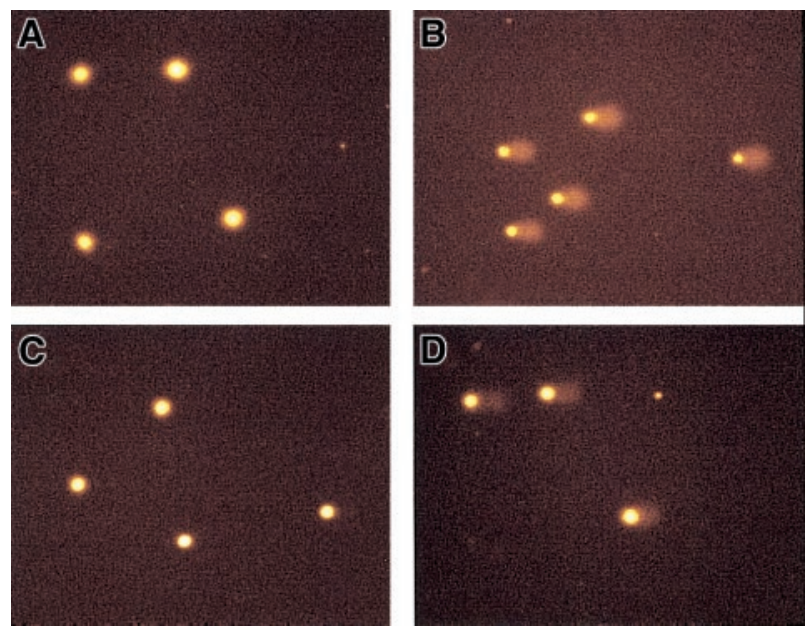

Figure 1. Typical comet images from plasma cells treated ex vivo with melphalan. After irradiation (10 Gy) of nondrug-treated plasma cells, distinct comets were observed $(B)$ when compared with nondrug-treated unirradiated plasma cells (A). After treatment with $50 \mu \mathrm{M}$ melphalan for 1 hour followed by 16 hours drug-free after incubation, no DNA single strand breaks were observed $(C)$. After irradiation of drug-treated plasma cells, comet tails were visible but with decreased length and intensity because of the presence of melphalan-induced ICL (D). All images stained with propidium iodide. Original magnification, $\times 20$.

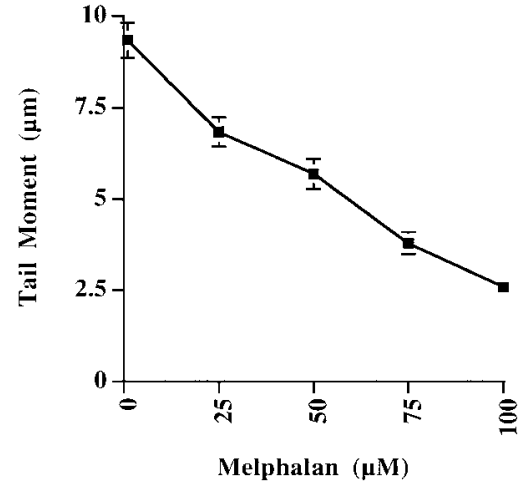

Figure 2. Effect of increasing dose of melphalan on the tail moment of plasma cells. Plasma cells were from a single patient, and results were expressed as mean tail moment \pm SE of 50 cells analyzed. A linear decrease in tail moment was observed with increasing dose of melphalan as a result of increasing ICL formation.

low as $1 \mu \mathrm{M}$. At each dose point the mean tail moment from 50 cells was quantitated, and variability was small, indicating that formation of melphalan-induced ICLs was homogeneous throughout the plasma cell population.

\section{Comparison of DNA ICL formation in plasma cells from melphalan-naive and melphalan-treated patients}

ICL formation was quantitated in plasma cells from 6 patients who were melphalan-naive and 6 patients previously treated with melphalan as shown in Figure 3. Data were expressed as the percentage decrease in tail moment as compared with nondrugtreated controls from the same patient. ICL formation was dose dependent with all patients displaying more than $70 \%$ crosslinking at $100 \mu \mathrm{M}$ (Figure 3A,B) regardless of previous melphalan exposure. No significant differences in ICL formation were seen between the 2 populations (Figure 3C), indicating that intracellular melphalan levels were similar in cells from each patient population, allowing an equal level of DNA alkylation.

\section{Comparison of DNA ICL repair in plasma cells from melphalan- naive and melphalan-treated patients}

Repair of melphalan-induced ICLs was studied in both patient populations 24 hours following the 16 hours after incubation required for peak of ICL formation (ie, 40 hours following initial drug exposure). Figure 4 shows representative comet images. Samples were taken from a melphalan-naive (Myeloma 1) and a patient who relapsed following a melphalan-conditioned autograft (Myeloma 2). Both patients showed a similar reduction in comet tail length because of the presence of melphalan-induced ICLs $(\mathrm{t}=16$ hours $)$ when compared with nondrug-treated irradiated control subjects (no melphalan). However, no repair of melphalaninduced ICLs at 40 hours was observed in plasma cells from the naive patient, and the reduction in comet tail persisted. In contrast, significant repair was observed in the relapsed patient, and the comet tail returns to a similar level as the nondrug-treated irradiated control subject.

The repair data from all patient samples is summarized in Table 2. No repair was seen in any of the 6 naive patients and was regardless of previous exposure to the VAD regime. In contrast all patients who had received prior melphalan therapy, both oral and high dose, displayed significant repair at 40 hours, ranging from $42 \%$ to $100 \%$. ICL repair was homogeneous throughout all the plasma cell populations. In some patients it was possible to detect ICL repair in sequential samples taken some months later. For 
Figure 3. Formation of melphalan-induced DNA ICLs in plasma cells isolated from melphalan-naive and melphalan-treated MM patients. ICL formation, as represented as percentage decrease in tail moment, increased with dose of melphalan to the same extent in both melphalan-naive (A) and melphalan-treated patient populations (B). No significant differences in ICL formation in melphalan-naive (-) and melphalan-treated (-- - -) patients were observed when expressed as mean percentage decrease in tail moment $\pm S E(C)$.

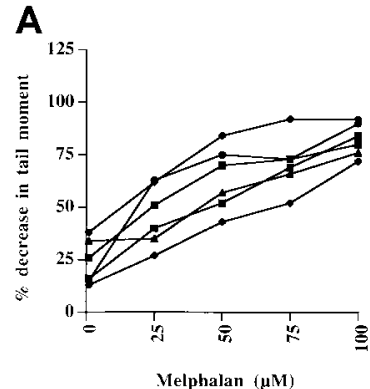

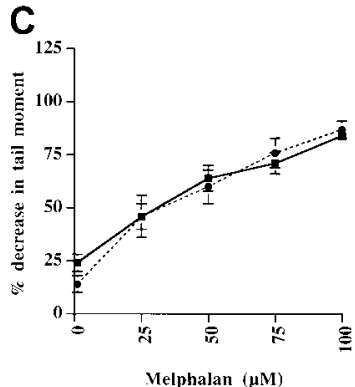

example, patient 9 demonstrated $54 \%$ repair at initial sampling (Table 2) compared with 58\% repair 13 months later, whereas patient 12 demonstrated $48 \%$ repair (Table 2) compared with $50 \%$ 4 months later. In one patient, patient 4 , samples were taken at initial diagnosis and at relapse following a melphalan-conditioned autograft (Table 2). No repair of melphalan-induced ICLs was observed prior to melphalan therapy. In contrast, $56 \%$ repair was seen in plasma cells taken at relapse after melphalan exposure.

The persistence of ICL in the naive patient population should result in increased sensitivity to melphalan. ${ }^{14}$ Indeed, when there were sufficient cell numbers to perform the MTT cytotoxicity assay, the in vitro sensitivity to melphalan in plasma cells was found to correlate with ICL repair (Table 2).

\section{Discussion}

The Comet assay has been used to detect both the formation and repair of melphalan-induced ICLs in plasma cells from 12 patients

\section{Myeloma 1}
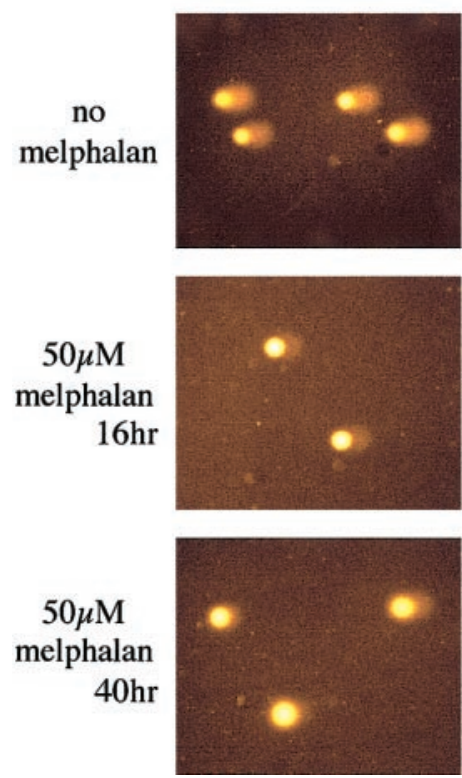

Myeloma 2
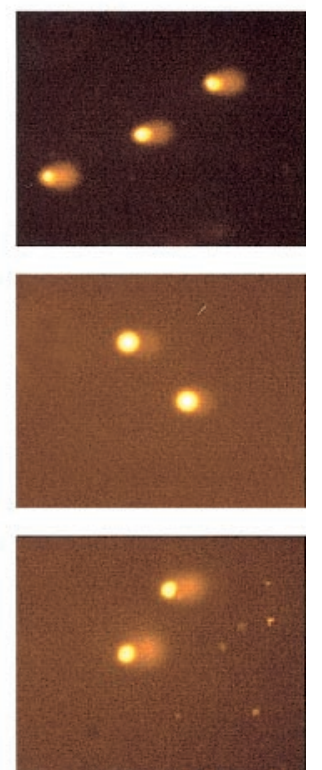

Figure 4. Analysis of melphalan-induced DNA ICL formation and repair in plasma cells using the Comet assay. Examples of comet images obtained from a melphalan-naive (Myeloma 1) and relapsed patient following melphalan-conditioned autograft (Myeloma 2). Both patients showed similar comet tail length following 10 Gy irradiation (no melphalan). Treatment with $50 \mu \mathrm{M}$ melphalan for 1 hour and subsequent incubation for 16 hours to allow maximum ICL formation ( $t=16$ hours) produced an equivalently reduced comet tail in both samples. At $t=40$ hours the same level of ICLs was still present in Myeloma 1. In contrast, in Myeloma 2 the comet tail length returned to a level similar to the irradiated control, revealing extensive repair of the ICLs. All images stained with propidium iodide. Original magnification, $\times 20$. with MM who were either melphalan naive or melphalan treated. The formation of melphalan-induced ICLs was found to be similar in both patient populations and was unaffected by previous melphalan exposure. This finding suggests that upstream resistance mechanisms such as drug transport and detoxification, although likely to be associated with VAD resistance, particularly the acquisition of the multidrug resistance phenotype, ${ }^{4,5}$ do not play a significant role in the development of melphalan resistance in MM. Such mechanisms have previously been found to show no correlation with resistance to nitrogen mustards in chronic lymphocytic leukemia (CLL). ${ }^{24,25}$

We have shown a marked difference in the ability to repair melphalan-induced ICLs between plasma cells from melphalannaive patients and melphalan-treated patients. Increased repair is independent of any previous treatment with VAD/CVAMP (cyclophosphamide, vincristine, adriamycin, methylprednisolone) and can be detected in both patients who have relapsed after a melphalan-conditioned autograft and those receiving oral melphalan therapy. The analysis of patient 4 at both initial presentation and relapse following a melphalan-conditioned autograft clearly illustrates the development of this mechanism after melphalan exposure. The ultimate aim is to study all patients at presentation and relapse; however, it must be noted that time to relapse following an autograft is approximately 3 years. ${ }^{1}$ The role of DNA repair in clinical resistance to agents such as the nitrogen mustards is becoming increasingly important. ${ }^{26,27}$ Sequential sampling from melphalan-treated patients indicates that similar levels of repair can be detected between intervals of several months prior to further therapy, indicating a stable phenotype. For example, at initial sampling patient 9 demonstrated 54\% repair compared with 58\% repair observed 13 months later. Because the Comet assay analyzes single cells, heterogeneity of response can be determined. The level

Table 2. Repair of melphalan-induced interstrand crosslinks in plasma cells and in vitro cytotoxicity to melphalan

\begin{tabular}{rlcc}
\hline Patient & Melphalan & \% Repair at $40 \mathrm{~h}$ & $\mathrm{IC} \mathrm{C}_{50}(\mu \mathrm{M})$ \\
\hline 1 & Naive & 0 & $\mathrm{ND}$ \\
2 & Naive & 0 & 15 \\
3 & Naive & 0 & $\mathrm{ND}$ \\
4 & Naive & 0 & $\mathrm{ND}$ \\
5 & Naive & 0 & 8 \\
6 & Naive & 0 & $\mathrm{ND}$ \\
7 & High dose & 100 & $\mathrm{ND}$ \\
8 & High dose & 72 & 55 \\
9 & High dose & 44 & $\mathrm{ND}$ \\
10 & High dose & 52 & 23 \\
4 & High dose & 56 & 39 \\
11 & High dose & 65 & $\mathrm{ND}$ \\
12 & Oral & 48 & 52 \\
\hline
\end{tabular}

$\mathrm{IC}_{50}$, dose of melphalan giving $50 \%$ inhibition of cell growth; ND indicates not determined. 
of repair was, however, found to be equivalent within an individual cell sample, suggesting that the underlying mechanism is homogeneous throughout the plasma cell population following melphalan therapy.

Resistance to melphalan and other nitrogen mustards has been studied in $\mathrm{CLL}^{26}$ and was found not to be the result of a drug transport defect or enhanced metabolism. ${ }^{25}$ However, significantly increased repair of melphalan-induced ICL was observed ex vivo in lymphocytes taken from patients with CLL known to be resistant to nitrogen mustards compared with untreated patients. ${ }^{28}$ A number of repair mechanisms have been studied in CLL in an attempt to elucidate the mechanism by which this increased removal of ICL occurs. No significant differences in the expression and activity of enzymes involved in base excision repair and nucleotide excision repair were seen in lymphocytes isolated from untreated patients and patients with CLL resistant to nitrogen mustard. ${ }^{29-31}$ However, a clear linear correlation between in vitro cytotoxicity to chlorambucil and DNA protein kinase activity and localization of DNA repair proteins suggests a possible role for recombinational repair processes. ${ }^{32,33}$ A similar role in MM has yet to be established.

Bifunctional alkylating agents such as melphalan are capable of producing a number of DNA adducts and, although the ICL is generally considered to be the cytotoxic lesion, ${ }^{10}$ it only constitutes a small proportion of the total adducts formed, the majority formed being monoadducts. Apurinic sites can result from monoalkylations that can be converted to DNA strand breaks under alkaline conditions and that could potentially interfere with the detection of ICLs by the Comet assay. However, no evidence of strand break formation was detected in any of the patients' unirradiated, melphalan-treated cells. Indeed, studies with mono-melphalan, which produces equivalent levels of monoalkylation to melphalan but is unable to form ICLs, ${ }^{34}$ have not revealed any significant formation of single strand breaks under the conditions used in the Comet assay (data not shown). Drug-induced apoptosis after melphalan treatment is possible particularly following the 40 hours after incubation. The Comet assay can be used to detect apoptosis within a single cell population. ${ }^{35}$ Because of the severe fragmentation of DNA during the apoptotic process, almost the entire DNA within a cell migrates to the tail and the tail characteristically appears "detached" from the head. In the cell populations analyzed in the present study however, the number of apoptotic cells was small and did not interfere with the analysis of ICLs.

We have clearly shown that repair of melphalan-induced ICLs may be the major mechanism for the development of melphalan resistance in MM. These data suggest that the role of melphalan as a preparative agent in MM may require further assessment particularly in patients who have previously received melphalan as a conditioning regime. This finding may be of relevance in patients undergoing a second transplantation as part of a tandem autograft protocol or as treatment of relapsed disease. The data also suggest that the Comet assay may be of value in both the detection of emergence of a resistant phenotype and the prediction of response to melphalan therapy in MM. The complex molecular mechanism by which human cells repair ICL is becoming established. ${ }^{27,36}$ The present study suggests that pharmacologic manipulation of this mechanism may be of value in optimizing the effect of repeated courses of melphalan chemotherapy.

\section{References}

1. Attal M, Harousseau JL, Stoppa AM, et al. A prospective, randomized trial of autologous bone marrow transplantation and chemotherapy in multiple myeloma. Intergroupe Francais du Myelome. N Engl J Med. 1996;335:91-97.

2. Barlogie B, Jagannath S, Desikan KR, et al. Total therapy with tandem transplants for newly diagnosed multiple myeloma. Blood. 1999;93:55-65.

3. McElwain TJ, Powles RL. High-dose intravenous melphalan for plasma-cell leukaemia and myeloma. Lancet. 1983;2:822-824.

4. Dalton WS, Grogan TM, Meltzer PS, et al. Drug resistance in multiple myeloma and non-Hodgkins lymphoma: detection of P-glycoprotein and potential circumvention by addition of verapamil to chemotherapy. J Clin Oncol. 1989;7:415-424.

5. Epstein J, Xiao HQ, Oba BK. P-glycoprotein expression in plasma cell myeloma is associated with resistance to VAD. Blood. 1989;74:913-917.

6. Valkov NI, Sullivan DM. Drug resistance to DNA topoisomerase I and II inhibitors in human leukaemia, lymphoma and multiple myeloma. Semin Hematol. 1997;34:48-62.

7. Moalli PA, Pillay S, Weiner D, et al. A mechanism of resistance to glucocorticoids in multiple myeloma: transient expression of a truncated glucocorticoid receptor mRNA. Blood. 1992;79:213-222.

8. Chauchan D, Kharbanda S, Ogata A, et al. Interleukin- 6 inhibits Fas-induced apoptosis and stress activated protein kinase activation in multiple myeloma cells. Blood. 1997;89:227-234.

9. Hartley JA. Alkylating agents. In: Souhami RL, Tannock I, Hohenberger P, Horiot J-C, eds. Oxford Textbook of Oncology. 2nd ed. Oxford, United Kingdom: Oxford University Press; 2002 : 639-654.

10. Sunters A, Springer CJ, Bagshawe KD, et al. The cytotoxicity, DNA crosslinking ability and DNA sequence selectivity of the aniline mustards mel- phalan, chlorambucil and 4-[bis(2-chloroethyl) amino]benzoic acid. Biochem Pharmacol. 1992; 44:59-64.

11. O'Connor PM, Kohn KW. Comparative pharmacokinetics of DNA lesion formation and removal following treatment of $L 1210$ cells with nitrogen mustards. Cancer Commun. 1990;2:387-394.

12. Moscow JA, Swanson CA, Cowan KH. Decreased melphalan accumulation in a human breast cancer cell line selected for resistance to melphalan. Br J Cancer. 1993;68:732-737.

13. Tew KD. Glutathione-associated enzymes in anticancer drug resistance. Cancer Res. 1994;54: 4313-4320.

14. Zwelling L, Michaels S, Schwartz $\mathrm{H}$, et al. DNA crosslinking as an indicator of sensitivity and resistance of L1210 leukaemia cells to cis-diaminedichloroplatinum (II) and L-phenylalanine mustard. Cancer Res. 1981;41:640-649.

15. Hansson J, Lewensohn R, Ringborg U, et al. Formation and removal of DNA crosslinks induced by melphalan and nitrogen mustard in relation to drug-induced cytotoxicity in human melanoma cells. Cancer Res. 1987;47:2631-2637.

16. Hartley JA, Beradini MD, Souhami RL. An agarose gel method for the determination of DNA interstrand crosslinking applicable to the measurement of the rate of total and "second-arm" crosslink reactions. Ann Biochem. 1991;193:131-134.

17. Kohn KW, Ewig RAG, Erickson LC, et al. Measurement of strand breaks and crosslinks by alkaline elution. In: Friedberg EC, Hanawalt PC, eds. DNA Repair. New York, NY: Dekker; 1981:379408.

18. Ostling O, Johanson KJ. Microelectrophoretic study of radiation-induced DNA damages in individual mammalian cells. Biochem Biophys Res Commun. 1984;123:291-298.

19. Spanswick VJ, Hartley JM, Ward TH, Hartley JA Measurement of drug-induced DNA interstrand crosslinking using the single cell gel electrophoresis (Comet) assay. In: Brown R, Boger-Brown U, eds. Methods in Molecular Medicine: Cytotoxic Drug Resistance Mechanisms. Vol 28. Totowa, NJ: Humana Press; 1999:143-154.

20. Hartley JM, Spanswick VJ, Gander M, et al. Measurement of DNA crosslinking in patients on Ifosfamide therapy using the single cell gel electrophoresis (Comet) assay. Clin Cancer Res. 1999; 5:507-512.

21. Webley SD, Francis RJ, Pedley RB, et al. Measurement of the critical DNA lesions produced by antibody-directed enzyme prodrug therapy (ADEPT) in vitro, in vivo and in clinical material. Br J Cancer. 2001;84:1671-1676.

22. Barlogie B, Smith L, Alexanian R. Effective treatment of advanced multiple myeloma refractory to alkylating agents. N Engl J Med. 1984;310:13531356.

23. Olive PL, Banath JP, Durand RE. Heterogeneity in radiation-induced DNA damage and repair in tumour and normal cells measured using the "comet" assay. Radiat Res. 1990;122:86-94.

24. Bramson J, McQuillan A, Aubin R, et al. Nitrogen mustards drug resistant B-cell chronic lymphocytic leukaemia as an in vivo model for crosslinking agent resistance. Mutat Res. 1995;336:269278.

25. Panasci L, Henderson D, Skalski V, et al. Transport, metabolism and DNA interaction of melphalan in lymphocytes from patients with chronic lymphocytic leukaemia. Cancer Res. 1988;48:19721976.

26. Panasci L, Paiement JP, Christodoulpoulos G, et al. Chlorambucil drug resistance in chronic lymphocytic leukaemia: the emerging role of DNA repair. Clin Cancer Res. 2001;7:454-461.

27. McHugh PJ, Spanswick VJ, Hartley JA. Repair of 
From www.bloodjournal.org at UCL Library Services on August 21, 2008. For personal use only.

DNA interstrand crosslinks: molecular mechanisms and clinical relevance. Lancet Oncol. 2001; 2:483-490.

28. Torres-Garcia SJ, Cousineau L, Caplan S, et al. Correlation of resistance to nitrogen mustards in chronic lymphocytic leukaemia with enhanced removal of melphalan-induced DNA crosslinks. Biochem Pharmacol. 1989;38:3122-3123.

29. Geleziunas R, McQuillan A, Malapetsa A, et al. Increased DNA synthesis and repair enzyme expression in lymphocyte from patients with chronic lymphocytic leukaemia resistant to nitrogen mustards. J Natl Cancer Inst. 1991;83:557-564.

30. Bramson J, McQuillan A, Panasci LC. DNA repair enzyme expression in chronic lymphocytic leukaemia vis-à-vis nitrogen mustard drug resistance. Cancer Lett. 1995;90:139-148.

31. Barret J-M, Calsou P, Laurent G, et al. DNA repair activity in protein extracts of fresh human malignant lymphoid cells. Mol Pharmacol. 1996;49: 766-771.

32. Muller C, Christodoulopoulos G, Salles B, et al. DNA-dependent protein kinase activity correlates with clinical and in vitro sensitivity of chronic lymphocytic leukaemia lymphocytes to nitrogen mustards. Blood. 1998;92:2213-2219.

33. Christodoulopoulos G, Malapesta A, Schipper H, et al. Chlorambucil induction of HsRad51 in B cell chronic lymphocytic leukaemia. Clin Cancer Res. 1999;5:2178-2184.

34. Tilby MJ, McCartney H, Gould KA, et al. A monofunctional derivative of melphalan: preparation. DNA alkylation products and determination of the specificity of monoclonal antibodies that recognize melphalan-DNA adducts. Chem Res Toxicol. 1998;11:1162-1168.

35. Nelms BE. Measuring apoptosis in individual cells with the Comet assay. Promega Notes. 1997;64: 13-16.

36. Wang ZM, Chen ZP, Xu ZY, et al. In vitro evidence for homologous recombinational repair in resistance to melphalan. J Natl Cancer Inst. 2001:93:1473-1478. 